\title{
El catolicismo político en Curazao 1936-1962
}

\section{Political Catholicism in Curaçao 1936-1962}

ARMANDO LAMPE / armando.lampe@gmail.com

Theologie interkulturell, Universidad de Frankfurt

\section{Resumen / Abstract}

En el presente trabajo se analiza el fracaso de la Iglesia católica en la política partidista de Curazao, no obstante que lideró un partido político en una sociedad mayoritariamente católica. Curazao era el centro del poder colonial holandés en el Caribe. Fue la época en que Indonesia proclamó su independencia de Holanda en 1945. A partir de ese acontecimiento Holanda se vio obligada a iniciar la descolonización de sus territorios en el Caribe, que culminó con su autonomía en 1954. La Iglesia católica tiene una presencia histórica en la isla que se remonta al siglo xvl; fundó un partido católico en 1936 pero, a pesar de su refundación, desapareció del mapa político en 1962. La Iglesia y los partidos políticos en Curazao son un tema poco conocido que aquí se estudia con fuentes del Archief Paters Dominicanen, de la provincia de Nimega, Holanda. Se concluye que el proceso de descolonización es el factor principal en la explicación del fracaso del partido católico.

\section{Palabras clave}

Curazao, descolonización, época colonial tardía, historia de la Iglesia católica, política y religión.
This paper analyses the failure of the Catholic Church in its incursion into party politics in Curaçao, notwithstanding its leadership role with a political party in the context of a largely Catholic population. During this period Curaçao was the centre for Dutch Colonial power in the Caribbean. This was the period during which Indonesia self-proclaimed independence from Holland in 1945, forcing Holland to initiate the decolonization for its Caribbean territories, culminating in autonomy in 1954. The Catholic Church maintains a presence in the island since the Sixteenth century and founded its political party in 1936, but despite re-founding the party, it finally disappeared from the political map in 1962. The Catholic Church and political parties in Curaçao is not widely researched and is discussed here using primary sources from the Archief Paters Dominicanen, from the Province of $\mathrm{Ni}$ mega, Holland. This article concludes that the decolonization process was the key factor leading to the demise of the Catholic political party in Curaçao.

\section{KeYWORDS}

Curaçao, Decolonization, History of the Catholic Church, Late Colonial Period, Religion and Politics. 


\title{
Le catholicisme politique à Curazao, 1936-1962
}

\section{Het politieke katholicisme in Curaçao 1936-1962}

\author{
ARMANDO LAMPE / armando.lampe@gmail.com \\ Theologie interkulturell, Universidad de Frankfurt
}

\section{RéSumé / Samenvatting}

Ce travail analyse l'échec de l'Église catholique dans la politique partisane à Curazao, alors même que l'Eglise a été à la tête d'un parti politique dans une société majoritairement catholique. Curazao était alors le centre du pouvoir colonial hollandais dans la Caraïbe. Le mouvement indépendantiste indonésien a déclaré son indépendance de la Hollande en 1945. Suite à cet événement, la Hollande a été obligée d'initier un processus de décolonisation de ses territoires dans la Caraïbe, processus qui a culminé avec leur autonomie en 1954. L'Église catholique a une présence historique dans I'île qui remonte au XVlème siècle; elle a fondé un parti catholique en 1936 mais, malgré sa refondation en 1948, celui-ci a disparu de la carte politique en 1962. L'Église et les partis politiques de Curazao sont un thème peu connu qui est étudié ici à partir des sources de l'Archief Paters Dominicanen, de la province de Nimega, en Hollande. L'article conclut que le processus de décolonisation est le principal facteur d'explication de l'échec du parti catholique.

\section{Mots-CLÉS}

Curazao, décolonisation, époque coloniale tardive, Histoire de l'Eglise catholique, religion et politique.
Dit is een analyse van de mislukking van de katholieke Kerk in de partijpolitiek van Curaçao ondanks het feit dat zij leider was van een politieke partij in een hoofdzakelijk katholieke samenleving. Curaçao was in die tijd het Nederlandse koloniale machtscentrum in de Cariben. In dezelfde tijd, 1945, riep de Indonesische onafhankelijkheidsbeweging aldaar de onafhankelijkheid uit van Nederland. $\mathrm{Na}$ die gebeurtenis was Nederland verplicht om een dekolonisatieproces te beginnen in de Caribische gebieden, wat leidde tot hun autonomie in 1954. De katholieke Kerk heeft een historische presentie op het eiland die teruggaat tot de zestiende eeuw. In 1936 stichtte zij een politieke partij, maar deze verdween van de politieke kaart in 1962, in weerwil van een heroprichting in 1948. De Kerk en de politieke partijen in Curaçao vormen een thema dat weinig bekend is en dat bestudeerd wordt op grond van bronnen uit het Archief Paters Dominicanen van de provincie van Nijmegen, Nederland. Vastgesteld wordt dat het dekolonisatieproces de belangrijkste factor is geweest die het echec van de katholieke partij verklaart.

\section{SLeUTELWOORDEN}

Curaçao, deskolonisatie, godsdienst en politiek, Katholieke Kerkgeschiedenis, laat-koloniale tijdperk. 


\section{Introducción}

En el presente trabajo abordo las relaciones entre la Iglesia católica y la política en Curazao, ${ }^{1}$ una isla situada cerca de la costa de Venezuela, que desde el 10 de octubre de 2010 es un país autónomo dentro del Reino holandés. Al hecho de que Curazao haya adquirido su autonomía política, con su propio gobierno y parlamento, le antecede una historia que se remonta hacia los años inmediatamente posteriores a la Segunda Guerra Mundial. Aquí se analizará la época del incipiente movimiento autonomista o de descolonización y el papel que desempeñó la Iglesia católica.

La Iglesia católica en Curazao -a diferencia de Surinam, otra colonia holandesa en el Caribe, independiente desde 1975- tiene un gran arraigo en el pueblo desde el siglo xvı. Aquí solo nos interesa el periodo delimitado por la fundación del primer partido católico en 1936 por el obispo de Curazao y la desaparición del segundo partido político en 1963, el cual fue fundado por otro obispo en 1948.

Curazao constituye un caso singular: no obstante que era una colonia holandesa los intentos por establecer un partido católico en la isla no fueron exitosos, como sí fue el caso de Holanda. En el presente trabajo pretendo aclarar las razones que llevaron a este rasgo específico de Curazao.

\section{El desarrollo del catolicismo}

Curazao fue invadido por los conquistadores de la península ibérica en 1499. Fue Ilamada "isla de los gigantes" por la estatura de los indígenas, que pertenecían a los caquetíos y formaban un pueblo con los de la península de Coro. Los obispos de Coro -diócesis

${ }^{1}$ Parte de este trabajo fue presentado como ponencia en el XIX Congreso de la Asociación Mexicana de Estudios del Caribe, los días 9-11 de abril de 2014, en la Universidad de Quintana Roo, Chetumal. Este artículo forma parte de mi proyecto de investigación sobre sacerdotes-políticos en la historia de la Iglesia católica en América Latina y el Caribe desarrollado con el apoyo de una beca de Alexander von Humboldt Stiftung. 
fundada en 1531- empezaron a llamarse también obispos de Curazao, Aruba y Bonaire. En 1638 se trasladó el obispado de Coro a Caracas, Curazao pertenecía entonces al obispado de Caracas. En 1634, cuando los holandeses invadieron Curazao, se conocían tres iglesias católicas. La libertad religiosa en esta isla era mayor que en cualquier otra colonia holandesa; como Curazao se convirtió en un puerto comercial importante, especialmente para el tráfico de esclavos, la cuestión religiosa no podía ser un obstáculo en los tratos comerciales, por eso las autoridades coloniales eran más tolerantes (Lampe, 2001).

Desde el siglo xvı el catolicismo era una práctica religiosa de los esclavos y de los miembros de este grupo reconocidos "libres". En Curazao, entre 85 y 90\% de la población era católica y no-blanca; de esta manera la separación entre blancos y no-blancos, entre amos y esclavos, era igual a la separación entre no-católicos y católicos. En 1863 fue abolida la esclavitud, pero no hubo cambio en el orden social. El cambio socioeconómico ocurrió en 1915 cuando se estableció la refinería petrolera Shell. Situado junto a la costa de Venezuela, un excelente puerto natural, siendo colonia holandesa, Curazao se volvió un centro productor importante del petróleo de Venezuela. En 1916, Curazao tenía una población de 33806 personas, de las cuales 31616 eran católicos, 1416 protestantes y 744 judíos (Lampe, 1987, p. 241). Esta era la situación peculiar de Curazao, es decir: un elevado número de católicos en una colonia dirigida por una élite protestante y gobernada por el Reino Holandés, tradicionalmente protestante. Curazao se convirtió en el centro del gobierno colonial, denominado "Curazao y las islas sumisas", ya que fue la isla más importante de las Antillas Neerlandesas, una entidad federativa creada por Holanda en 1954, integrada por Aruba, Bonaire, San Martín, San Eustaquio y Saba, y que existió hasta el 10 de octubre de 2010 (salvo Aruba, que salió de la Federación Antillana Neerlandesa en 1986). 


\section{El proceso de descolonizaciōn}

El colonialismo refiere, según la definición de la International Encyclopedia of the Social Sciences, al dominio de pueblos de otra cultura, que habitan tierras separadas del centro imperial por el mar. La primera expansión sistemática de Europa se dio en el Caribe a partir de 1492, y existía una relación entre la misión cristiana y el colonialismo en el sentido de que la misión era un forma de legitimación colonial (Reinhard, Linkenbach-Fuchs y Fuchs, 2015, p. 33). El primer paso de la descolonización -que es el proceso de conseguir la independencia política de la colonia- también se dio en el Caribe con la Revolución haitiana que culminó con la independencia de Haití en 1804, hasta entonces colonia francesa. En general, se puede decir que la independencia política significaba una mayor dependencia de la economía mundial (Wesseling, 1997, pp. 124125). La descolonización, término introducido en la década de los treinta y también Ilamado fin del imperio (Jansen y Osterhammel, 2013, p. 10), no significó el final de la dominación. Por eso colonización / descolonización no solamente refiere a un proceso externo, la actitud arrogante del centro se encuentra tanto en los países colonizadores como en los países colonizados (Betts, 1998, p. 96). Consecuentemente, hay que revisar nuestra concepción lineal y progresiva de la historia de la colonización, como si hubiese empezado en el siglo xv con el mal llamado "descubrimiento" y finalizado en el siglo xx con la descolonización (Ferro, 1997, p. 211). Curazao sigue siendo parte del Reino holandés, a pesar de los cambios estatales en 2010, mientras que Surinam logró salir de ese reino con su independencia política en 1975. Curazao no es el único territorio no-independiente del Caribe, estatus que comparte con Puerto Rico, los departamentos de ultramar de Francia y otros territorios ingleses (Ramos y Rivera, 2001).

La iniciativa oficial holandesa de descolonización empezó en 1940, cuando Holanda estaba inmersa en la Segunda Guerra Mundial. Esa iniciativa culminó con la proclamación de la Constitución 
del Reino Holandés en 1954. El gobierno de Holanda mantenía una política conservadora con respecto a Indonesia como colonia, para conservarla dada su importancia económica y no obstante que tenía ya 70 millones de habitantes, mientras que la población de Holanda era de apenas nueve millones (Oostindie y Klinkers, 2001, p. 15). Pero la ocupación de Indonesia por Japón en 1942 tuvo un profundo impacto en la política holandesa de descolonización. En el mismo año las tropas americanas ocuparon las islas de Curazao y Aruba, en una decisión concertada con Holanda, por la importancia que tenían para los aliados las refinerías de estas dos islas. Después de la ocupación de sus territorios, la política holandesa hacia sus colonias no podía ser igual. El 6 de diciembre de 1942 la reina Wilhelmina prometió desde Londres la gobernación autónoma en los asuntos internos de sus colonias. Ese viraje en la política holandesa fue impuesta por los aliados: en 1941 Roosevelt y Churchill firmaron el Atlantic Charter que definió la guerra contra la Alemania nazi como una guerra contra toda forma de opresión de los pueblos y por el derecho de cada pueblo a la autodeterminación.

Después de que Indonesia proclamara en forma unilateral su independencia política, el gobierno de Holanda inició el proceso de decir adiós al colonialismo en sus territorios del Caribe. En 1947 se nombró al doctor Moisés Frugencio da Costa Gomez -uno de los protagonistas del periodo analizado- como representante de las Antillas en las deliberaciones con el gobierno holandés. En 1948 empezó la Primera Conferencia de Mesa Redonda en La Haya y fue entonces que Da Costa Gomez utilizó por primera vez el nombre de Constitución del Reino Holandés (Statuut). En 1949 se formalizó la entrega de poder a la Indonesia independiente. En 1952 se reanudó la Conferencia de la Mesa Redonda en La Haya con representantes de los gobiernos de Holanda, Surinam y las Antillas, y de nuevo Da Costa Gomez desempeñó un papel clave en la aceptación del concepto por una constitución del Reino holandés. Holanda se negaba a aceptar el principio del derecho a la autodeterminación de los pueblos, una exigencia de los representantes de Surinam y las Antillas 
Neerlandesas, pero finalmente lo aceptó y se pudo proclamar la Constitución del Reino Holandés, que otorgó la autonomía a los territorios de Holanda en el Caribe el 15 de diciembre de 1954. Las Naciones Unidas reconoció este hecho como el fin de las relaciones coloniales de Holanda. Surinam y las Antillas Neerlandesas adquirieron así en 1954 el estatus de selfgoverning territories, donde Holanda solo tenía la última palabra en el ámbito de la defensa militar y de las relaciones exteriores. La Segunda Guerra Mundial resultó así decisiva en el proceso de descolonización en el Caribe, proceso iniciado hacía casi 150 años con la independencia de Haití en 1804.

\section{Partidos políticos}

El primer partido político en la historia de Curazao fue católico, ha recibido poca atención de los investigadores y es objeto de este estudio. Fue fundado el 23 de enero de 1936 con el nombre de Curacaosche Rooms Katholieke Partij (CRKP): Partido Católico Romano de Curazao, que mostraba mucha similitud con el partido católico de Holanda. El obispo de Curazao, fundador del partido, invitó a M. F. da Costa Gomez para formar parte de la directiva. Da Costa Gomez asumió el liderazgo, pero en 1948 renunció por diferencias fundamentales con el clero. Fundó entonces su propio partido, el Nationale Volks Partij (Nvp): Partido Nacional del Pueblo. En el mismo año el nuevo obispo de Curazao fundó el segundo partido católico, el Katholieke Volks Partij (KVP): Partido Católico del Pueblo, que no fue un éxito electoral y después de 1963 dejó de participar en las elecciones.

En 1944 fue fundado el Democratische Partij (DP): Partido Demócrata, que logró romper la división política fincada en la creencia religiosa. Identificado como el partido de la élite protestante, que temía un dominio del partido católico por ser mayoría la población católica, proclamó el principio de la libertad e igualdad, independientemente de la religión profesada. En cierto sentido el partido de Da Costa Gomez (NVP) compartió el mismo principio: el Estado no 
podría tener preferencia por alguna denominación religiosa (Hoetink, 1969, pp. 149 y 397).

El político más destacado del periodo en estudio fue sin duda Moises Frugencio da Costa Gomez (Curazao, 27 de octubre de 1907-22 de noviembre de 1966). Estudió la carrera de Derecho en la Universidad Católica de Nijmegen, en Holanda, y en 1935 obtuvo el doctorado en Derecho en la Universidad de Ámsterdam. El título de su tesis doctoral Ilevaba el significativo título Het wetgevend orgaan van Curacao, samenstelling en bevoegdheid bezien in het kader van de Nederlandse koloniale politiek (El órgano legislativo de Curazao en el contexto de la política colonial holandesa). Desde 1937 hasta 1963, salvo algunas interrupciones, formó parte del órgano legislativo de Curazao. En 1942 fue nombrado miembro del Consejo Extraordinario de Consulta del gobierno holandés en Londres. En 1949 desempeñó por algunos meses el cargo de presidente del Colegio de Gobernación General de Curazao y las otras islas, y de 1951 a 1954 fue presidente del Consejo de Gobierno. Del 28 de junio de 1963 hasta la fecha de su fallecimiento fue miembro del poder ejecutivo de Curazao (gedeputeerde, que no se puede traducir como diputado, ya que en América Latina significa miembro del poder legislativo). En el periodo 1946-1954 fue presidente de las delegaciones antillanas en las Conferencias de la Mesa Redonda y tuvo una contribución muy importante en la Constitución del Reino Holandés (Statuut) que en 1954 dio autonomía de gobierno a las colonias holandesas en el Caribe (Hoetink, 1969, p. 262). El pueblo lo llamaba Doctor para expresar su admiración por ese líder carismático.

En 1937 se realizó la primera elección en la historia de Curazao, aunque con un sistema de sufragio limitado, donde solo $6 \%$ de la población masculina podía votar, y de los quince miembros del Parlamento solo diez pudieron ser electos, los otros cinco fueron designados por el gobernador. El partido católico (CRKP) consiguió seis de los diez escaños y Da Costa Gomez se volvió líder de la fracción católica (Reinders, 1993, p. 33). El sufragio universal fue 
introducido hasta 1948, y en 1950 quedó establecido el régimen de "responsible government", un gobierno propio de las Antillas Neerlandesas, electo por el pueblo mediante elecciones libres y generales, y que debía responsabilizarse ante el Parlamento, integrado por representantes del pueblo. Esto significó el fin de una etapa en la historia colonial en la cual la responsabilidad gubernamental y legislativa ya no era de Holanda sino de los pueblos del Caribe holandés (Reinders, 1993, p. 11).

Si analizamos el desempeño electoral del partido católico a partir de 1948 llegamos a los siguientes datos (Reinders, 1993). En las elecciones del 17 de marzo de 1949, cuando Curazao tenía ocho escaños en el Parlamento, el Katholieke Volks Partij (KVP) logró uno, mientras que el Nationale Volks Partij (NVP) de Da Costa Gomez ganó cuatro. En 1950 cambió la Constitución y a Curazao le asignaron doce escaños de 21 del Parlamento; en las elecciones del 21 de diciembre de 1950 el KVP obtuvo dos escaños y el NVP cinco; en las del 15 de diciembre de 1954 el partido católico perdió un escaño y el de Da Costa Gomez mantuvo la mayoría de cinco. Cuatro años después, en los comicios del 1 de septiembre de 1958 el kvp solo se quedó con uno, mientras que el NVP aumentó un escaño y Ilegó a seis. En las votaciones del 4 de junio de 1962 el partido católico perdió su único escaño y eso benefició al partido de Da Costa Gomez que logró la cantidad histórica de siete. Después de 1962 el partido católico ya no participó en ninguna elección y su destino fue de una muerte silenciosa. Estos datos revelan que el kvp fue un fracaso electoral y que el pueblo católico apoyó no al partido católico del obispo de Curazao, sino al exlíder del partido católico, el doctor Da Costa Gomez, el enemigo político del obispo. La desobediencia electoral del pueblo católico de Curazao fue una experiencia amarga e inexplicable para el clero. 


\section{La intervención de la Iglesia católica en la política}

El término catolicismo político no se refiere a la relación general que hay entre la Iglesia y la política, entendida como toda actividad enfocada hacia el bien común (Buchanan y Conway, 1996), pues es obvio que la Iglesia como institución tiene un impacto sobre la política en general. Este término refiere a la política específica, entendida como política partidista y donde la Iglesia católica ha participado activamente como institución. Podemos señalar al caso del Partido Católico Nacional (PCN) fundado en México en 1911, como un exponente del catolicismo político. En Curazao también se dio, aunque más tarde, con el partido católico fundado por el obispo de Curazao. Y por eso es tan apropiado también para ese caso el término de catolicismo político, porque es la Iglesia la que promovía un partido político. Es un campo de estudio poco analizado, otros estudiosos del Caribe insular han dedicado trabajos al tema de Iglesia-Estado, o más amplio al tema protestantismo-política o catolicismo-política, pero no a estudios de caso sobre el catolicismo político en el Caribe insular, quizá porque no se conoce en otras subregiones del Caribe insular el fenómeno de partidos católicos, un tema que seguramente hay que investigar más a fondo en el futuro.

A diferencia del resto del Caribe holandés, la Iglesia católica en Curazao tiene profundas raíces históricas en el pueblo (Lampe, 2001). Los esclavos, traídos de África a Curazao, fueron convertidos a la Iglesia católica desde el siglo XVII, mientras que la clase dominante local eran protestantes y judíos; así, la separación entre la clase opresora y la clase oprimida adquirió una connotación racial y religiosa: Ios negros y oprimidos pertenecían a la Iglesia católica. La Iglesia tenía toda una tradición de intervención en el terreno social, político y económico; desde el inicio del siglo xIx impulsó un sistema educativo para el pueblo pobre; en casi todos los barrios populares surgían escuelas católicas. Otra peculiaridad de Curazao fue que el gobierno colonial decidió financiar la escuela católica igual que la escuela pública. 
Al comenzar el siglo xx la Iglesia promovió el movimiento cooperativista, el clero fundó muchas cooperativas de producción para los pobres. En 1919 se fundó la Liga Popular Católica, promovida principalmente por el dominico holandés Verriet, después obispo de Curazao en 1932. La Liga organizó a los obreros, y por su inspiración surgieron varios sindicatos católicos (Lampe, 1987). Fue el obispo P. I. Verriet, quien fundó el primer partido católico de Curazao el 23 de enero de 1936, el Curacaosche Rooms Katholieke Partij (CRKP), en cuya directiva estaba el doctor Moises F. Da Costa Gomez.

Otra peculiaridad de Curazao fue que la tarea evangelizadora estuvo a cargo de misioneros de holandeses (sacerdotes dominicos), situación que perduró hasta 1973 cuando entraron predicadores de otros países. Como en Holanda funcionó el partido católico, el clero pensó que ese modelo iba a funcionar también en una colonia holandesa en el Caribe. En Holanda se tenía una larga tradición de sacerdotes-políticos: desde 1883, el padre Herman Schaepman (18441903) fue durante 23 años miembro del Parlamento holandés, en representación del partido católico. Otro famoso sacerdote-político, el padre W. H. Nolens (1860-1931), fue miembro del Parlamento de 1896 a 1931, también representando al partido católico. Ese fenómeno fue denominado por algunos historiadores con el término ya mencionado catolicismo político (Luykx, 1996). La historia del partido católico de Holanda estaba directamente ligada a la historia del partido católico de Curazao, en el sentido de que el primero fue modelo para el segundo.

En Holanda el partido católico fue un éxito porque respondía al reto de la emancipación católica; es decir, la población católica formaba una minoría dominada por una mayoría protestante y donde en el siglo xix los católicos estaban excluidos de muchas funciones públicas. Los católicos de Holanda se habían organizado políticamente, con el apoyo de la jerarquía, para defender los derechos de los católicos. Los misioneros holandeses introdujeron el modelo holandés en Curazao, pero Curazao no es Holanda. Si en 
Holanda el reto fue la emancipación católica, en Curazao, donde apenas se abolió la esclavitud en 1863, el reto fue la emancipación de la población negra, que representaba la emancipación racial y social de la mayoría, y no la emancipación religiosa de una minoría como fue el caso del país colonizador. R. A. Römer (1974, p. 23), en su obra sociológica argumenta que la emancipación del esclavo no se realizó por el decreto del 1 de julio de 1863, con la abolición de la esclavitud, sino que duraría décadas y seguía siendo un reto en el siglo $x x$.

Curazao fue un producto colonial de Holanda que creó una sociedad esclavista. El clero holandés, con una mentalidad colonial, fundó el partido católico en la isla pensando que en Curazao también se trataba de responder al reto de la emancipación católica como en Holanda; resultó un fracaso. El partido católico participó en 1936 por vez primera en las elecciones en un contexto colonial y elitista con un sistema de sufragio limitado, porque fue hasta un año después, en 1937, que se introdujo el sufragio universal. En su primera salida electoral en un sistema de sufragio limitado en 1937 el partido católico salió victorioso y el doctor Da Costa Gomez fue el líder de la fracción parlamentaria. Después de 1937 Da Costa Gomez siguió siendo líder del partido católico, pero en 1945 sufrió su mayor derrota electoral ante el nuevo partido (DP), que representaba a la élite blanca de Curazao, a pesar de que la mayoría del pueblo era católica.

Los misioneros holandeses no podían entender el fracaso del partido católico porque leían la realidad de Curazao desde la perspectiva de Holanda; buscaron entonces un chivo expiatorio y lo encontraron en la persona de Moises da Costa Gomez, el presidente de la fracción parlamentaria católica. Para ellos, Da Costa Gomez no era suficientemente católico; esta opinión de los padres holandeses Ilevó a una división dentro del partido; es decir, Da Costa Gomez lo abandona para fundar uno propio. 


\section{El fracaso del partido católico}

Después de la división del partido católico el clero holandés creó en 1948 uno nuevo Ilamado Katholieke Volks Partij (KVP): Partido Católico del Pueblo. El fundador fue de nuevo un obispo, esta vez le tocó el honor a monseñor Van der Veen Zeppenfeldt; así pasó a la historia el KVP como el partido del obispo Mons. Van der Veen Zeppenfeldt, vicario apostólico de las Antillas holandesas. ${ }^{2}$

Antoninus Lewis Jacob van der Veen Zeppenfeldt nació en Aruba el 11 de octubre de 1891. El apellido de su madre era Thielen, el de su padre Van der Veen Zeppenfeldt. Fue el primer sacerdote dominico de las Antillas Neerlandesas, el primer sacerdote de Aruba y el primer obispo de origen criollo; todos los obispos anteriores provenían de Holanda. Ingresó a la orden de los frailes dominicos de la provincia holandesa e hizo sus votos perpetuos el 23 de septiembre de 1912. Fue ordenado sacerdote el 15 agosto de 1918 y trabajó en diferentes parroquias hasta que fue nombrado vicario apostólico de las Antillas Neerlandesas en 1948. Para ejercer esa función el papa lo nombró obispo de Acholla (una sede episcopal que ya no existe) y fue ordenado obispo el 30 de diciembre de 1948. Escogió estas palabras para su programa episcopal: "Veritas, justitia, caritas" (Marcha, 2005, pp. 82-87). Su nombre estaba tan vinculado con el Partido Católico del Pueblo (KvP) que hasta el nuncio de Haití, que era responsable también para la diócesis de Willemstad, hablaba del kvp como el partido del obispo ("le parti de l'évêque"). ${ }^{3}$

El partido del obispo Van der Veen Zeppenfeldt (KVP), creado en 1948, compitió por primera vez con el nuevo partido de Da Costa Gómez (NVP) el 17 marzo de 1949, y terminó en una derrota aplastante al obtener solo un escaño. La campaña electoral giraba alrededor de los mensajes "Vota lista no. 1, color geel. Vota catolico. Fuerte

${ }^{2}$ Archief Paters Dominicanen (en adelante APD), carpeta NR 1976, que contiene la correspondencia del padre provincial y la documentación sobre la situación política de Curazao en 1947 y 1948, titulada: Correspondentie van de provinciaal en documentatie met betrekking tot de politieke situatie op Curaçao, 1947-1948.

${ }^{3}$ APD, carta del vicario de los Dominicos de las Antillas Neerlandesas dirigida al padre provincial en Nimega el 1 de julio de 1949. 
den Fe. Catolico tur ora" " Hay que votar por la primera lista, el partido de color amarillo, hay que votar por el catolicismo, fuerte en la fe, siempre católico") y aunque el pueblo era mayoritariamente católico muy pocos votaron por el partido católico. El NVP ganó las elecciones y el Dr. Da Costa Gomez se integró al nuevo gobierno. El resultado electoral fue decepcionante para el obispo, quien pensó que el pueblo católico lo iba a obedecer; el clero culpó entonces al pueblo de no ser suficientemente católico. ${ }^{4}$

En la siguiente elección (1950) el KVP obtuvo menos votos aún no obstante que un sacerdote nuevamente era candidato (el padre Willers, un dominico holandés). El partido del obispo siempre tenía un cura como consejero. En las elecciones de 1954 -cuando fue creado el Parlamento de las Antillas Neerlandesas- el partido católico apenas pudo mantener un escaño. Después de estos resultados ya no había futuro para este partido y desapareció del mapa político. Monseñor Van der Veen Zeppenfeldt no pudo aceptar esa derrota, deprimido, ya no pudo funcionar como obispo. ${ }^{5}$ El obispo evitaba cualquier contacto con el gobierno formado por el partido contrario, lo cual resultaba en grandes problemas para el funcionamiento de la misión de Willemstad; finalmente, el Vaticano pidió su renuncia del obispo, quien la presentó el 18 de marzo de 1956.

Van der Veen Zeppenfeldt no pudo entender el fenómeno Da Costa Gomez; incluso cuando aún no era obispo, lo caracterizó como anticomunista, anticatólico y fascista para alertar a las autoridades del partido católico en Holanda sobre el peligro inminente que amenazaba a los intereses de la Iglesia en Curazao, esto en el informe de una misión secreta que realizó en Holanda entre el 4 y el 26 de febrero de 1948, ${ }^{6}$ por encargo de L. Teeuwen, padre provincial de la Provincia Holandesa de los Padres Dominicos.

${ }^{4} \mathrm{APD}$, carta del vicario de los Dominicos en Curazao al padre provincial en Nimega el 1 de julio de 1949.

${ }^{5} \mathrm{APD}$, Informe secreto de 1956.

${ }^{6} \mathrm{APD}$, carpeta NR 1796. 
En ese informe se refería a la presencia de Da Costa Gomez en la Conferencia de Mesa Redonda en La Haya, donde se empezó a discutir la descolonización holandesa tras la independencia de Indonesia en 1945. Van der Veen Zeppenfeldt caracterizó como comunista a la mayoría de la delegación parlamentaria de Curazao que atendió aquella histórica conferencia: "Da Costa Gomez es miembro del Partido Comunista de Holanda", así se puede leer en el Informe secreto, ${ }^{7}$ en el que se hace referencia al "Gomez fascista", quien "buscaba contacto con los comunistas" en Curazao. El mensaje de su informe era siempre el mismo: los intereses de la Iglesia católica estaban en peligro por el supuesto anticatolicismo de Gomez, quien además de ser considerado comunista no era confiable y solo quería destruir al partido católico.

Pero esa opinión no era algo aislado. Algunos historiadores argumentan que en respuesta a la amenaza de perder a la clase obrera ante los partidos socialistas y comunistas, la Iglesia y el clero lanzan a escala internacional una ofensiva anticomunista con la fundación de partidos políticos, como se puede leer en el número Concilium Revista Internacional de Teología dedicado al tema "La Iglesia y los partidos políticos" (Concilium, núm. 213, 1987). Había dos motivos interrelacionados detrás del anticomunismo del clero. Por un lado el clero tenía miedo del ateísmo y materialismo, y que la lucha de clases atrajera a los obreros católicos. Por otro, la mayoría de la masa católica eran los obreros, y cualquier éxito socialista era visto como una amenaza para la unidad de la Iglesia, unión que tenía que prevalecer ante todo. Surgieron sindicatos católicos, bajo la guía del clero, para asegurar la lealtad de los obreros; el discurso del clero era francamente anticomunista, en rechazo a cualquier colaboración con los rojos socialistas. El discurso anticomunista de monseñor Van der Veen Zeppenfeldt era acorde a la misión católica de esa época respecto a hacer todo lo posible para conservar a la clase obrera bajo la tutela de la Iglesia.

${ }^{7}$ APD, carpeta NR 1796.

104 - Revista Mexicana del Caribe 21 / 2016 (pp. 90-117) 
En 1937 el papa Pío IX publicó la encíclica Divini redemptoris, que condena el comunismo ateísta. Ante la mayor identificación del comunismo con la ideología materialista y atea, la Iglesia lanza una contraofensiva. Ya en la encíclica Rerum novarum de 1891, el papa León XIII toma posición en contra del socialismo y comunismo. Cuando fracasaron las negociaciones por un concordato entre la Unión Soviética y el Vaticano en 1927 y se desata una política leninista-stalinista de eliminar la religión considerada como opio del pueblo, se refuerza el anticomunismo de la Iglesia. El 1 de julio de 1949 el papa Pío XII publica un decreto de la Santa Sede que excomulgaba a cualquier católico que colaborara de forma activa o pasiva con el comunismo. El motivo real de este decreto fue la amenaza de una toma de poder en Italia por los comunistas y el papa Pío XII apoyaba a los demócrata-cristianos. Se trata de un anticomunismo ideológico de la Iglesia, para distinguirlo de otras formas de anticomunismo, que es un concepto complejo que se debe estudiar más a fondo.

Miedo y anticomunismo se volvieron sinónimos en la guerra fría. Más que nada el anticomunismo del obispo Van der Veen Zeppenfeldt fue motivado por miedo. La cultura del miedo en la era de la guerra fría generó una histeria colectiva en contra de un chivo expiatorio (Greiner, 2014, p. 29). El enemigo no real, pero imaginado por el obispo, producto de esa histeria fue el Dr. Da Costa Gomez. La perspectiva anticomunista del obispo le impidió valorar a Da Costa Gomez, uno de los primeros criollos que obtuvo su doctorado en Derecho en la prestigiosa Universidad de Ámsterdam en Holanda, que fundó su propio partido, el NVP -que existe hasta hoy y que sigue en el gobierno de Curazao-, y se volvió el símbolo de la emancipación del pueblo colonizado por su lucha a favor de la autonomía en contra del colonizador de Holanda. Da Costa Gomez, el Doctor (como le llamaba el pueblo), logró después de la Segunda Guerra Mundial -cuando Indonesia conquistó la independencia política de Holanda en 1945- la creación del país autónomo Antillas Neerlandesas dentro del Reino holandés en 1954, el cual existió como país 
hasta el 2010, pero lo que pasó después de ese año y el proceso que llevó a ese desenlace no son temas de interés de este artículo.

\section{El conflicto de interpretaciones del fracaso del partido católico}

Dos testigos de la época nacidos en Curazao publicaron su interpretación del fracaso del partido católico. El primero fue el colaborador más cercano de Da Costa Gomez, Hendrik G. M. Pieters Kwiers, un alto funcionario público que ocupó varios cargos en el poder legislativo y ejecutivo en representación del Partido Nacional del Pueblo.

Pieters Kwiers (1991, p. 105) afirma que fue el mismo Da Costa Gomez quien tomó la decisión de romper con el primer partido católico para crear un nuevo partido. Da Costa Gomez fue uno de los 40 invitados por monseñor Verriet para fundar el partido católico en vista de la primera elección el 20 de diciembre de 1937, basada en el sufragio limitado a una élite y cuando la mitad del órgano legislativo era directamente nombrado por el gobernador como autoridad colonial. Tanto en las elecciones de 1937 como en las del 17 de noviembre de 1941 el partido católico, sin una competencia real, tuvo éxito electoral, siendo Da Costa Gomez el líder de la fracción; pero en 1945, cuando solo la élite podía votar, triunfa el Partido Demócrata (DP), fundado en 1944, el cual representaba los intereses de la élite protestante y se manifestaba a favor de mayor autonomía. Ante esa derrota electoral, Da Costa Gomez toma la decisión de fundar un nuevo partido católico. El punto de ruptura fue, según Pieters Kwiers (1991, p. 45), que el partido católico estaba en contra de la causa de la autonomía, mientras que Da Costa Gomez la defendía.

Según Pieters Kwiers las diferencias de opinión entre Da Costa Gomez y la directiva del partido católico surgieron desde 1943. El clero, que tenía una visión paternalista del pueblo, decía que este no estaba suficientemente maduro para una primera ruptura con el orden colonial, que aún era ignorante para ejercer el sufragio 
universal, mientras que Da Costa Gomez era un defensor del derecho del pueblo para gobernarse sin la intervención de Holanda, idea central de su tesis de doctorado, defendida ya en 1935. El nuevo Partido Democrático supo leer los signos de los tiempos y adoptó un discurso a favor del derecho de tener un gobierno propio, y tuvo éxito.

Da Costa Gomez, en forma clandestina, empezó a formar su propio partido, cuya bandera principal iba a ser la lucha por la autonomía de Curazao. En 1948, por iniciativa de Pieters Kwiers (1991, p. 52), hubo un encuentro con monseñor Verriet. El mensaje del obispo fue que si creaban un nuevo partido, entonces se tenía que suprimir el partido católico, porque la división de los católicos iba a favorecer al enemigo común, que para el obispo era el DP, por estar ligado a la élite protestante (Pieters Kwiers, 1991, p. 54.). Mons. Verriet dio su palabra de que el clero pediría el apoyo de los católicos para el nuevo partido de Da Costa Gomez, que si bien se le definiría como un partido de los católicos no llevaría esa denominación. Dos días después falleció el obispo, y su sucesor, monseñor Van der Veen Zeppenfeldt, pensaba diferente; fundó el kvp, al que denominó partido católico, pensó que los católicos lo seguirían a él y no a Da Costa Gomez, pero no resultó así (Pieters Kwiers, 1991, p. 105).

Cuando Da Costa Gomez quiso nombrar al fraile Radulphus ${ }^{8}$ como secretario de Educación en su gobierno (Hoetink, 1969, p. 477), monseñor Van der Veen Zeppenfeldt le prohibió aceptar el cargo, porque no podía colaborar con un "traidor" a la causa católica (Pieters Kwiers, 1991, p. 106). De acuerdo con la información de Pieters Kwiers, los obispos seguían pensando en la lógica de católicos-no católicos, cuando la realidad de la posguerra en Curazao se regía por la lógica de colonización-descolonización.

El segundo testigo de la época fue Amado E. J. Römer (19222010), sacerdote y luchador social, doctorado en Teología por la

${ }^{8}$ El fraile Radulphus (1869-1961) pertenecía a la Congregación de Frailes de Tilburg y fue director de la fundación para la educación católica desde 1907; inspector de las escuelas católicas y reconocido como un gran organizador. 
Universidad Gregoriana en Roma y doctorado honoris causa por la Universidad de Curazao. Fue una figura excepcional, simplemente por el hecho de haber sido uno de los pocos sacerdotes nacidos en Curazao y pionero del sindicalismo y cooperativismo en la isla (Boessenkool y Swank, 2010).

A. E. J. Römer (1997, p. 42) confirma que el primer partido católico fue por iniciativa del obispo Verriet. Römer (1997, p. 43) menciona que monseñor Verriet. pidió que se nombrara consejero del partido católico a su secretario personal, el padre dominico Irenaeus de Bruin, quien Ilevó una lucha feroz en la isla de St. Barthélemy contra los anticlericales y los anticatólicos, lo que confirma que la lógica era la de la lucha por la causa católica. Römer (1997, p. 63) subraya que la ruptura entre Da Costa Gomez y el partido católico fue la diferencia de opinión fundamental acerca de la descolonización, ya que Da Costa Gomez era un defensor del derecho del pueblo a gestionar sus propios asuntos separado de Holanda, mientras que el clero estaba en contra de la causa de la autonomía.

Siguiendo esta línea de interpretación, Römer (1997, pp. 6566) menciona que tiene pruebas (que ya no existen en el Archivo de la Diócesis pues se quemó el 30 de mayo de 1969) de que el fracaso electoral del partido católico en 1945 fue por la crítica inoportuna de los periódicos católicos en contra de Da Costa Gomez, y la propaganda negativa de miembros del clero en contra del líder de la fracción católica en el órgano legislativo, precisamente porque Da Costa Gomez siempre favorecía la causa de la autonomía. Römer (1997, p. 76) no puede ocultar su admiración por Da Costa Gomez, quien inclusive le da el título de "profeta". Pero el joven sacerdote Amado Römer, una singular personalidad de Curazao, representaba una voz en el desierto ya que el clero de entonces estaba integrado casi exclusivamente por dominicos de Holanda.

Una diferencia de opinión entre Römer y Pieters Kwiers es que según Römer fue el obispo Verriet quien tomó la iniciativa de llamar a diferentes personas para preguntar su opinión sobre la derrota del partido católico en 1945, pero Pieters Kwiers menciona 
que fue él quien tomó la iniciativa para concertar una cita con el obispo. Siguiendo el orden cronológico ambos tienen razón, pero en fecha distinta. Römer se refiere a la ronda de consulta convocada por el obispo a partir de 1945, mientras que Pieters Kwiers habla de una reunión en 1948 después de que Da Costa Gomez estuvo trabajando clandestinamente en la fundación de un nuevo partido entre 1945 y 1948, el cual ya no podía ocultar al señor obispo. Pero ambas interpretaciones de la época coinciden en que el punto de ruptura en el partido católico fue la cuestión de la autonomía ante el orden colonial.

Römer menciona además un intento de mediación del monseñor Verriet, quien pensó en invitar como mediador del partido católico de Holanda al profesor Rommer, quien tenía mucha autoridad, pero murió en forma repentina. Römer aporta otros datos para corroborar el punto de ruptura. Da Costa Gomez representaba a Curazao en la Conferencia de La Haya, convocada por la reina Wilhelmina para hablar sobre la descolonización, y resultó ser el defensor más ferviente de la causa de la autonomía. Pero la directiva del partido católico de Curazao envió un telegrama de protesta, firmado por Ch. B. Debrot, en contra de esa causa, argumentando que el pueblo no estaba maduro para manejar sus propios asuntos, y además desautorizó a Da Costa Gomez, pues él no podía hablar en nombre del kvP de Curazao (Römer, 1997, p. 78). Cuando el secretario del obispo, el padre Möhlman, critica a Da Costa Gomez públicamente en el periódico católico, la ruptura es un hecho.

Según Römer (1997, p. 80), el clero propuso a Van der Veen Zeppenfeldt, oriundo de la élite local, para ser el nuevo obispo, y su primera iniciativa fue fundar un nuevo partido católico bajo el liderazgo de J. H. Sprockel, I Debrot y el padre Möhlman, secretario del obispo. Van der Veen rechaza públicamente al partido de Da Costa Gomez y su causa de la autonomía. Römer concluye que a partir de allí ya no hubo ningún contacto más entre el partido de Da Costa Gomez y la misión católica. El obispo usó el mismo nombre del partido católico de Holanda (KVP) y declaró que este partido era 
parte esencial de la misión católica. El desenlace ya lo conocemos, y después de la muerte de monseñor Van der Veen Zeppenfeldt el partido católico se fusionó en 1963 con el DP, el partido de la élite, y, según Römer (1997, p. 99), significó también la muerte del partido católico en Curazao. El sucesor de Van der Veen Zepenfeldt, monseñor Holterman, prohibió al partido católico seguir usando el nombre de católico, porque casi todo el pueblo lo era y no tenía sentido dividir a la Iglesia como pueblo de Dios por razones políticas. En la década de los sesenta surge una nueva era en la historia política de Curazao y también en la Iglesia católica con la realización en Roma del Segundo Concilio Vaticano (1962-1965), que va a renovar a la Iglesia clerical, dando más participación a los laicos.

\section{Una interpretaciōn sociológica}

En su tesis de doctorado Peter Verton ofrece una interpretación sociológica del surgimiento y declive del partido católico. Verton (1977, p. 43) argumenta que en la fase colonial tardía, a partir de 1936, la competencia política se libraba entre católicos y no católicos. En la Constitución de 1936 se reglamentó que diez de los quince miembros del Ilamado Órgano Legislativo fueran electos, y los otros cinco fueron nombrados por el gobernador.

Antes de 1936 el Consejo Colonial, nombrado por el gobernador, solo tenía la facultad de dar consejo. En 1937 se introdujo el sufragio limitado donde solo podía votar $6 \%$ de la población masculina, elegida con base en su declaración de impuestos y su grado de escolaridad. El partido católico participó en la elección de 1937 con relativo éxito. Pero cuando se introdujo el sufragio universal en 1948 y hubo una ruptura en el partido católico la división política ya no se basaba en la identidad católica, ya que casi todo el pueblo era católico, sino en otros criterios sociales. El partido católico, según Verton (1977, p. 67), apoyó de una forma demasiado tímida el proceso de descolonización y eso lo puso en desventaja con los demás partidos. Para Verton, los objetivos pastorales de querer unir a 
todo el pueblo le impidieron asumir una postura más radical a favor de la descolonización.

Verton (1977, p. 67) considera que los líderes de los partidos políticos a partir de 1948 asumieron el rol de los "shons", es decir, de los amos blancos de la sociedad esclavista. En vez de depender de un amo blanco, el pueblo pasa a depender del líder del partido político para su ascenso social. No sólo el sufragio universal hizo al pueblo menos dependiente de los amos blancos, sino también el desarrollo económico. Las clases subalternas se liberaron de la dependencia de los shons a partir del establecimiento de la refinería petrolera Shell en Curazao en 1917, y este "boom" económico trajo a muchos trabajadores migrantes del Caribe. Curazao pasó de ser una sociedad esclavista a una sociedad de migrantes. El DP, que originalmente definía su identidad en ser no católico, se adaptó a las nuevas circunstancias y se definió como un partido de migrantes y de la clase obrera establecida en la ciudad.

El partido de Da Costa Gomez abrazó la causa de la autonomía y del pueblo en el campo que quería liberarse de los amos blancos. Por todo eso la élite blanca perdió su poder y los partidos políticos se convirtieron en nueva forma de movilidad social a partir de 1948; el partido católico quedó rebasado por ese desarrollo social y perdió su relevancia para las masas que querían emanciparse socialmente. Se trata de una interpretación válida, pero no es suficiente si tomamos en cuenta el contexto internacional de partidos católicos.

\section{Una interpretaciōn histórica}

El fenómeno de los partidos católicos conoció sus éxitos electorales en el continente europeo. En Bélgica el Partido Católico (Katholieke Partij) tuvo una historia de más de un siglo, desde la primera mitad del siglo xIx hasta la segunda mitad del xx, y sus victorias electorales fueron posibles por el consejo del voto de párrocos, obispos y cardenales. En Alemania surgió en 1870 el partido católico (Zentrumspartei), y entre 1871 y 1918 de los 478 miembros del Parlamento 91 
fueron sacerdotes católicos; entre 1920 y 1928 un sacerdote católico fue ministro de Labor, Heinrich Brauns, quien tenía el apodo de Heinrich el Eterno por haber sobrevivido varios gobiernos de diferentes signaturas, pero siempre gobernando el partido católico; en 1933 desapareció el partido católico por una medida magistral de Hitler: a cambio de su aprobación del Concordato de 1933 exigió la supresión del partido católico (Lampe, 2013, nota 28, p. 228). En Holanda el partido católico (primero RKSP y después KVP, Katholieke Volks Partij) tuvo éxitos electorales desde 1883 hasta la década de los sesenta del siglo xx cuando se integró a la democracia cristiana (Christen Democratisch Appel [CDA]), un partido de signatura cristiana y no solo católica, que gobernó Holanda hasta la primera década del siglo xxı.

En Curazao, en cambio, el partido católico fue un fracaso electoral. Hay raíces históricas profundas que pueden explicar tal fracaso. En Holanda los historiadores han utilizado el concepto de pilarización (verzuiling), para decir que el partido católico estaba inserto en el pilar católico y en las organizaciones y que esto explicaba su éxito electoral (Luykx, 1996, p. 226). En un país donde la mayoría era protestante, la minoría católica tenía que marcar su territorio: desde la decoración de su casa, las escuelas de sus hijos, las librerías donde compraban sus libros, la panadería donde compraban su pan, el sindicato donde militaban, todo tenía que ser católico, y así también su voto político. La palabra pilar se volvió un concepto estándar dentro de la comunidad de historiadores para describir este fenómeno. El uso del término pilarización indica que la sociedad, la cultura, y la política de Holanda estaban profundamente marcados por este fenómeno. No solo se aplica este término a los católicos, sino también a los protestantes, los socialistas y los liberales, pues era una sociedad basada sobre diferentes pilares.

Pero Curazao no conoció este fenómeno de pilarización. Algunos historiadores sociales han usado otro término para caracterizar a Curazao: el de sociedad segmentada. Rob van Lier fue el primero en usar en 1954 este término para el caso de Surinam. 
Después Harry Hoetink lo aplicó a la sociedad de Curazao. Rob van Lier describía a la sociedad de Surinam como una sociedad segmentada, que consistía de diferentes grupos culturales separados por raza, etnicidad, lenguaje, religión y niveles económicos, que coexistían pero que rara vez se mezclaban. Hoetink defendió su tesis de doctorado sobre la sociedad segmentada de Curazao en 1958 y después publicó sus dos obras clásicas (Hoetink, 1967, 1973). La sociedad de Curazao era una sociedad segmentada, consistía de diferentes grupos culturales segmentados por raza y posición social, con sus propias instituciones: arriba estaba la élite blanca europea y protestante ligada al poder colonial desde 1634, en medio los comerciantes judíos sefárdicos, que Ilegaron en el siglo XVII, y abajo la masa negra, descendientes de los esclavos que llegaron de África. Efectivamente, en 1863, cuando se abolió la esclavitud en Curazao, $85 \%$ de la población era afrocurazaleña, de la cual $35 \%$ fue esclava en 1863 (Allen, 2007, p. 27).

A esa distinción racial y social surgió una nueva característica en esa sociedad segmentada: el elemento religioso. A partir del siglo XVII las autoridades coloniales protestantes toleraron la misión católica, desde las colonias españolas, entre los esclavos de Curazao para no poner en riesgo las relaciones comerciales con el continente español y perjudicar el contrabando hacia Ámsterdam a través del puerto de Curazao, así surgió un grupo esclavo que a la vez era católico (Lampe, 2001). Los segmentos sociales estaban históricamente divididos desde el siglo xvı por una minoría blanca, protestante o judía y de posición social alta o media, y una minoría negra, católica y pobre. Con el tiempo ha habido cruces sexuales entre los segmentos, pero las relaciones de poder a base de esta segmentación perduró hasta la rebelión obrera del 30 de mayo de 1969.

Entre la pilarización de la sociedad en Holanda y la segmentación de la sociedad en Curazao había una diferencia fundamental: Curazao era una sociedad colonizada que surgió de una sociedad esclavista. Para entender por qué el partido católico tuvo éxito en Holanda pero fue un fracaso en Curazao tenemos que recurrir a este 
último aspecto. En ese contexto histórico de Curazao el grupo subalterno buscaba su emancipación, que no llegó con la abolición de la esclavitud en 1863, a través de un proceso de descolonización. Cuando el partido católico bajo la tutela del clero blanco no optó por la causa de la autonomía de la colonia, vino la ruptura con Da Costa Gomez quien se volvió el líder de la causa de la autonomía, y las masas católicas se fueron con Da Costa Gomez. Su punto de identificación no era su religión, sino la búsqueda de descolonización, y esto explica el fracaso del partido católico en Curazao. A una conclusión similar sobre la posición colonial del clero llega la historiadora Marit Monteiro de la Universidad de Nijmegen, quien escribió la historia de los dominicos holandeses, al constatar que el discurso de los misioneros en Curazao era colonial y que actuaban dentro del orden colonial que construía subalternidad basada en el color racial (Monteiro, 2008, p. 332).

\section{Conclusiōn}

En este artículo he mostrado que el caso de Curazao, una colonia holandesa, era un caso singular. Curazao no ha conocido un partido católico exitoso análogo a lo que pasó en Holanda, el país colonizador. En Holanda, como en Alemania, la formación de un partido católico fue para una minoría religiosa el medio con el cual podía preservar su identidad y adquirir la igualdad de derechos. Curazao era una isla donde la gran mayoría eran católicos que buscaban su emancipación social pero no religiosa. Este elemento, sin embargo, no explica del todo el fracaso del partido católico en Curazao. Italia fue un país mayoritariamente católico y, sin embargo, un partido católico tuvo éxito en ese país. La verdadera explicación debe buscarse en el proceso de descolonización que atravesaba la sociedad de Curazao, el clero que creó al partido católico estaba a favor de mantener el estatus colonial mientras que la mayoría buscaba mayor independencia de Holanda como una forma de afianzar su identidad no holandesa. Eso explica la singularidad de Curazao, 
pero es necesario hacer más estudios sobre la relación entre la empresa misionera católica y el colonialismo en Curazao. El ex líder del partido católico, Da Costa Gomez, quien sí abrazó la bandera de la autonomía, rompe con el partido católico y arrasa las masas en busca de su identidad en una sociedad posesclavista y colonial.

Estamos también en la época de la guerra fría. Con la perspectiva anticomunista el obispo Van der Veen Zeppenfeldt no podía entender la realidad. Vio erróneamente el primer movimiento anticolonial de Curazao, que estaba bajo el liderazgo de Da Costa Gomez, como una amenaza comunista. El anticomunismo en la época de la guerra fría ha impedido a muchos jerarcas ver la realidad, y monseñor Van der Veen Zeppenfeldt perdió contacto con la realidad por su anticomunismo y no pudo ubicar al Dr. Moises Da Costa Gomez dentro de la creciente tendencia anticolonial en las colonias holandesas después de la Segunda Guerra Mundial, que a su vez estaba inserto en la corriente mundial de descolonización en África, Asia y el Caribe. No obstante, hay que reconocer que el tema no está agotado, se deben estudiar más a fondo las diferentes funciones del anticomunismo de la Iglesia católica en la sociedad de Curazao, y la investigación futura sobre el papel de la misión católica en una sociedad colonial debe tomar en cuenta que la Iglesia católica no es una institución homogénea y que ha habido diversidad dentro de la misión.

\section{Fuentes citadas}

\section{ARCHIVO}

Archief Paters Dominicanen (APD), Nimega, Holanda

Carpeta NR. 1796 Correspondentie van de provinciaal en documentatie met betrekking tot de politieke situatie op Curaçao, 1947-1948 (nr. 1796, 1 omslag). 


\section{Armando Lampe}

REFERENCIAS

Allen, R. M. (2007). Di ki manera? A social history of afro-curaçaoans, 1863-1917. Ámsterdam: Uitgeverij SWP.

Betts, R. F. (1998). Decolonization. Londres / Nueva York: Routledge.

Boessenkool J. y Swank, M. (2010). Dat maakt de mens, de missie van Amado Römer. Ámsterdam: Uitgeverij SWP.

Buchanan, T. y Conway, M. (Eds.) (1996). Political catholicism in Europe, 1918-1965. Oxford: Clarendon Press.

Concilium, Revista Internacional de Teología (1987). La Iglesia y los partidos políticos (213). Madrid: Ediciones Cristiandad.

Ferro, M. (1997). Colonization: A global history. Londres / Nueva York: Routledge.

Greiner, B. (2014). Antikommunismus, angst und kalter krieg. Eine erneute Annäherung. En Creuzberger, S. y Hoffmann, D. (Eds.). "Geistige Gefahr" und "Immunisierung der Gesellschaft", Antikommunismus und politische kultur in der frühen Bundesrepublik (pp. 2941). Munich: Oldenbourg Verlag.

Hoetink, H. (1967). The two variants in Caribbean race relations: A contribution to the sociology of segmented societies. Londres: Oxford University Press.

Hoetink, H. (Ed.) (1969). Encyclopedie van de Nederlandse Antillen. Ámsterdam: Elsevier Nederland N. V.

Hoetink, H. (1973). Slavery and race relations in the Americas: Comparative notes an their nature and nexus. Nueva York: Harper and Row.

Jansen, J. C. y Osterhammel, J. (2013). Dekolonisation. Das ender der imperien. Munich: Verlag C. H. Beck.

Lampe, A. (1987). La Iglesia católica y la clase obrera en Curazao: 1922. Revista Mexicana de Sociología (3), 239-246.

Lampe, A. (2001). Mission or submission? Moravian and catholic missionaries in the dutch Caribbean during the $19^{\text {th }}$ century. Göttingen, Alemania: Vandenhoeck \& Ruprecht.

Lampe, A. (2013). Political celibacy. 1983 as a turning point in the Roman Catholic Church for priests-politicians. En Burlacioiu, C. y Hermann, A. (Eds.). Veränderte landkarten. Auf dem weg zu einer polyzentrischen geschichte des weltchristentums. Festschrift für 
Klaus Koschorke zum 65 Geburtstag (pp. 223-239). Wiesbaden, Alemania: Harrassowitz Verlag.

Luykx, P. (1996). The Netherlands. En Buchanan, T. y Conway, M. (Eds.). Political catholicism in Europe, 1918-1965 (pp. 219-247). Oxford, Inglaterra: Clarendon Press.

Marcha, V. (Ed.) (2005). Onze katholieke bisschoppen. Een historische schets van het beleid van de Rooms-Katholieke kerkhoofden voor de eilanden Aruba, Bonaire, Curaçao, St. Eustatius, St. Maarten en Saba. Ámsterdam: Uitgeverij SWP.

Monteiro, M. E. (2008). Gods predikers: Dominicanen in Nederland (17952000). Hilversum: Verloren.

Oostindie, G. y Klinkers, I. (2001). Het koninkrijk in de Caraïben. Een korte geschiedenis van het nederlandse dekolonisatiebeleid, 19402000. Ámsterdam: Amsterdam University Press.

Pieters Kwiers, H. G. M. (1991). Ideal polítiko di dr. Da Costa Comez, su lucha pa kambia e kòrsou bieu pa un kòrsou nobo. Willemstad, Curazao: Autor.

Ramos, A.G. y Rivera A. I. (Eds.) (2001). Islands at the crossroads: Politics in the non-independent Caribbean. Boulder: Lynne Rienner Publishers.

Reinders, A. (1993). Politieke geschiedenis van de Nederlandse Antillen en Aruba, 1950-1993. Zutphen: Walburg Pers.

Reinhard, W., Linkenbach-Fuchs, A., y Fuchs, M. (Eds.) (2015). Individualisierung durch christliche mission? Wiesbaden: Harrassowitz Verlag. (Studies in the History of Christianity in the Non-Western World, vol. 24).

Römer, A. E. J. (1997). Korsou den siglo xx. Desaroyo di un pueblo of tragedia, Willemstad, Korsou: Autor.

Römer, R. A. (1974). Naar de voltooiing van de emancipatie: beschouwingen naar aanleiding van het verschijnsel 30 mei. Willemstad, Curazao: Hogeschool van de Nederlandse Antillen.

Verton, P. (1977). Politieke dynamiek en dekolonisatie. De Nederlandse Antillen tussen autonomie en onafhankelijkheid. Holanda: Alphen aan den Rijn: Samsom.

Wesseling, H. L. (1997). Imperialism and colonialism. Essays on the history of European expansion. Londres: Greenwood Press. 